\title{
Library Services to the Graduate Community: Introduction
}

\section{$\mathrm{T}$} HE PRIMARY CHARACTERISTIC that distinguishes universities from other types of higher education institutions is the emphasis and priority that they place upon graduate education and research. University libraries must, consequently, place a similar priority and emphasis upon meeting the needs of the graduate students and research-oriented faculty who compose the university graduate community. Traditionally, university libraries have focused their efforts, in this area, upon developing the large and complex collections which we have long recognized as essential to support quality graduate and research programs.

In recent years it has become increasingly obvious that this is insufficient. As research and scholarly publication continue to proliferate, the problems of successfully and quickly accessing the information that they need have become substantial for faculty and, particularly, for graduate students.

Consequently, university librarians are recognizing that they must play a much stronger role in assisting this critical clientele-and particularly graduate students-to gain effective access to the

Eldred R. Smith is director of university libraries, State University of New York at Buffalo. As chairperson of the ACRL University Libraries Section, he presided at the program on library services to the graduate community at the ALA Conference in San Francisco, July 1, 1975, and this introduction to the three following articles is based on his remarks given at that program. information that they need and to develop an awareness of the complex bibliographical structure of the literature of their field.

Substantial efforts have been or are in the process of being made in this direction in a number of university libraries. The articles by Connie R. Dunlap, Anne Grodzins Lipow, and Thomas J. Michalak will address this topic in relation to three such efforts which, despite their differences, have two critical features in common. First, they each involve a substantial investment by their libraries, particularly of quality professional time and effort. Second, they have each met with very positive response.

The articles are not intended, necessarily, as models for other institutions to follow. Rather, they should indicate ways that have been found or are being found to meet a basic issue that confronts us all. Finally, they should help to demonstrate that, even in the difficult fiscal period that lies ahead, the issue is not "can we afford to provide these services" but rather "can we afford not to." I, for one, am convinced that we can and must continue to develop and expand quality service programs for our graduate clientele. Hopefully, we can concurrently continue our present efforts toward improving the cost-effectiveness of basic operations and the internal reallocation of staff resources so that we can invest an increasing amount of our high-cost professional resources and efforts in such service programs. 